\title{
Narrativa sobre um poder afável: trabalho e racionalidade neoliberal em Estou me guardando para quando o Carnaval chegar ${ }^{1}$
}

\section{Narrative on a gentle power: work and neoliberal rationality in Waiting for the Carnival}

Marcio Serelle 


\section{Resumo}

Neste artigo, analiso o documentário Estou me guardando para quando o Carnaval chegar (Brasil, 2019), de Marcelo Gomes, sobre o trabalho na cidade de Toritama, centro de produção de jeans, no agreste pernambucano. A hipótese é de que a narrativa não apenas registra a racionalidade neoliberal que conduz as personagens, mas a desafia por meio da forma fílmica. Logo, ainda que as entrevistas sejam parte importante do documentário, busco examinar outras estratégias audiovisuais que atuam na evidenciação desse poder que autores como Byung-Chul Han e Dardot e Laval consideram afável ou mesmo invisível.

Palavras-Chave

trabalho, racionalidade neoliberal, Estou me guardando para quando o Carnaval chegar, documentário, Marcelo Gomes.

\section{Abstract}

The article analyzes the documentary Waiting for the Carnival (Brazil, 2019), directed by Marcelo Gomes, about work in the city of Toritama, a jeans production center, in Pernambuco, Brazil. The hypothesis is that the narrative not only registers the neoliberal rationality that guides the workers of the city, but also highlights and confronts it in film form. Therefore, even considering interviews as an important element of the documentary, I try to examine other audiovisual strategies that disclosure this power that authors such as Byung-Chul Han and Dardot and Laval consider affable or even invisible.

\section{Keywords}

Work, Neoliberal rationality, Waiting for the Carnival, documentary, Marcelo Gomes. 
Neste artigo, abordo o documentário Estou me guardando para quando o Carnaval chegar (Brasil, 2019), de Marcelo Gomes, sobre o trabalho em Toritama, cidade do agreste pernambucano, produtora de jeans, de aproximadamente 45 mil habitantes. No filme, moradores da cidade, capturados pela racionalidade neoliberal, fazem longas jornadas de trabalho braçal e repetitivo sob a crença de que são donos do próprio negócio. O trabalho só é interrompido no Carnaval, quando se torna imperativo passar a festa na praia, nem que para viajar ao litoral os indivíduos tenham que vender seus objetos - máquinas de costura, celulares, televisão, geladeira, entre outros.

Interessa-me compreender como Estou me guardando... não apenas registra a racionalidade neoliberal, mas a desafia por meio da forma fílmica. Logo, ainda que as entrevistas sejam parte importante do documentário, busco examinar também outras estratégias audiovisuais que atuam na evidenciação desse poder que autores como Byung-Chul Han (2018) e Dardot e Laval (2017) consideram afável ou mesmo invisível.

A sutileza do neoliberalismo reside na sua lógica motivacional. Seu poder se manifesta não de forma opressora, mas silenciosamente, ao gerir por meio do agrado e ter como alvo o desejo dos indivíduos. "O sujeito submisso não é nunca consciente de sua submissão" (HAN, 2018, p. 26). Como Dardot e Laval (2017) apontam, o neoliberalismo é uma forma de governo das mentes que naturaliza o modelo concorrencial e a noção da empresa de si. O sujeito deve administrar as fases da vida como se estivesse gerenciando uma empresa. Na flexibilidade que propõe, a racionalidade neoliberal enfraquece os vínculos solidários e elimina formas de seguridade social. "A vida, a saúde e o amor são precários, por que o trabalho escaparia dessa lei?", afirmou Laurence Parisot, líder empresarial francesa (PARISOT citado por DARDOT; LAVAL, 2017, p. 347). Assim, o neoliberalismo faz a apologia do risco e afirma que a precariedade é uma forma de oportunidade, pois cabe aos indivíduos de espírito comercial - o empreendedor - aproveitar as chances de lucro. Logo, qualquer fracasso é também de responsabilidade do indivíduo, o que tem resultado em várias formas de sofrimento psicossocial. 
O neoliberalismo "não transforma os explorados em revolucionários, mas sim em depressivos" (HAN, 2018, p. 16).

Estou me guardando... integra um conjunto amplo de filmes que busca interpretar e denunciar a racionalidade neoliberal e a atual crise do trabalho flexível, de baixa remuneração, que expropria o tempo livre e resulta na autoexploração do sujeito. Se Vera Follain de Figueiredo, Tatiana Oliveira Siciliano e Eduardo Miranda (2019) perceberam o retorno do tema do trabalho no cinema de ficção brasileiro atual, após ele estar ausente no final do século passado, neste artigo, identifico como a questão é também candente no documentário contemporâneo global. Nesse contexto, Estou me guardando... é tanto uma contribuição para o debate acerca de aspectos locais de uma racionalidade que é mundial como, pela singularidade e capacidade crítica de sua forma, para a produção documental sobre o tema e de modo geral.

Este artigo possui três partes além desta introdução e das considerações finais. Na primeira delas, discuto, ainda que de forma breve, os aspectos da racionalidade neoliberal e as estratégias desse poder. Contextualizo Estou me guardando... num panorama cinematográfico em que emergem narrativas que buscam apontar as mistificações dessa racionalidade no mundo atual do trabalho. A partir de Nichols (2005), proponho, então, compreender a singularidade da voz desse documentário como um conjunto articulado de elementos audiovisuais que produz a crítica social. Na segunda parte, constato como a indústria da moda tem servido à crítica sobre a exploração do trabalho e sugiro elementos para o entendimento do fenômeno. Passo à análise da fílmica, o modo como principalmente a composição dos planos equaliza máquina e indivíduo, fábrica e lar, proporcionando a reflexão acerca da expropriação do tempo. O último segmento é sobre a narração e aspectos autorreflexivos desse documentário. A voz do narrador-diretor opõe memória e presente capitalista, explicita aspectos do dispositivo do documentário e maneja recursos audiovisuais para tentar amainar a angústia do maquinal. Pretendo, assim, refletir sobre como, no filme, a consciência audiovisual contribui para pôr a nu nossa condição neoliberal. 


\section{Poder afável e documentário}

A frase "Proteja-me do que eu quero", exibida na década de 1980 num luminoso em Manhattan, é uma das obras mais conhecidas de Jenny Holzer, que inclusive deu nome à exposição da artista estadunidense em São Paulo, em 1999. Com letras maiúsculas para competir com outros painéis eletrônicos, a frase remete mais diretamente ao consumo, mas também a outras formas de vício. Já na condição de epígrafe de Psicopolítica, de Byung-Chul Han (2018), ela se refere à autoexploração no trabalho contemporâneo. Afinal, o sujeito neoliberal, o sujeito do desempenho, considera-se livre quando, de fato, "é um servo absoluto, na medida em que, sem um senhor, explora voluntariamente a si mesmo" (HAN, 2018, p. 10). O regime neoliberal promove o estreitamento entre liberdade e exploração. O sujeito acredita-se livre por, à diferença do proletário, não se submeter ao empregador, mas como o sujeito é ele próprio uma empresa, totalizase o trabalho, sem coerções. "A psicopolítica neoliberal é uma política inteligente que busca agradar em vez de oprimir" (HAN, 2018, p. 53, grifo do autor).

Uma das declarações mais reiteradas do diretor Marcelo Gomes sobre seu documentário Estou me guardando... é a de que as personagens do filme concordavam em dar entrevistas desde que não precisassem interromper o trabalho na produção do jeans em Toritama ${ }^{3}$. A afirmação sustenta a surpresa do diretor, que esperava encontrar, baseado nas memórias de infância (ele visitava a cidade quando criança, acompanhando o pai, funcionário do Estado), uma sociedade pré-industrial. "Era um mundo rural e de feiras livres. De plantadores de milho e feijão e criadores de bode. Quase nenhum barulho"4. Essas são as primeiras frases do documentário, com a tela ainda escura. O espectador toma conhecimento dessa Toritama do passado principalmente pela voz do narrador-

Ver as entrevistas concedidas à revista Trip e ao programa Metrópolis, da TV Cultura, disponíveis em: https://revistatrip.uol.com.br/trip/o-diretor-marcelo-gomes-fala-sobre-o-documentario-estou-me-guardando-paraquando-o-carnaval-chegar e https://tvcultura.com.br/videos/70121_entrevista-com-marcelo-gomes-diretor-deestou-me-guardando para-quando-o-carnaval-chegar.html. Acesso em: 18 fev. 2020. 
diretor, que conduz o documentário, e por algumas poucas persistências desse mundo que são apresentadas no filme (retornarei a isso adiante).

O narrador-diretor se depara, entretanto, com a cidade rendida ao neoliberalismo. Os depoimentos dos entrevistados no filme, que trabalham nas facções (unidades caseiras de produção segmentada do jeans), confirmam isso. "O melhor é trabalhar para você mesmo". "Quanto mais arrochar o nó, mais você ganha". "Quem pensa que a vida da gente é ruim, está enganado". "Aqui, somos os donos. Entramos e saímos na hora que queremos". Em jornadas que se iniciam às 7 horas e vão até as 22 horas, os entrevistados, com algumas dissonâncias, enunciam variações de um mesmo discurso a favor da vida empreendedora, pois ela escaparia à subordinação. Para Dardot e Laval (2017), o sujeito empreendedor é a origem do sujeito-empresa, que maximiza seus resultados expondo-se ao risco. Tem-se, portanto, percepção pejorativa do emprego. Ele não é uma forma contratual de proteção ao trabalhador, mas, sim, índice de controle, exploração, falta de liberdade e baixo rendimento financeiro.

As longas jornadas, os ambientes simplórios, os corpos suados nas tarefas difíceis e repetitivas, as crianças que, soltas nas facções, adotam o maquinário como brinquedo e a ausência de dinheiro para aproveitar o Carnaval na praia evento que titula o filme a partir de canção de Chico Buarque - indicam o aspecto ilusivo da racionalidade neoliberal. Para Virgínia Fontes (2017, p. 50), a pessoa jurídica, como forma de empreendedorismo, é "apagamento [...] fictício da relação real de subordinação do trabalho ao capital, que se apresenta como igualdade entre... capitalistas, sendo um deles mero "proprietário" de sua própria força de trabalho". Proletário, como recupera Han (2018, p. 15), é "literalmente aquele que tem como única propriedade a própria prole". Mas a racionalidade liberal cuja lógica normativa é a competição generalizada e a empresa como modelo de subjetivação (DARDOT; LAVAL, 2016) torna o trabalhador um empreendedor e tira-Ihe essa perspectiva. Estou me guardando... trata dessa ilusão.

Figueiredo, Siciliano e Miranda (2019) já haviam atentado para o retorno do trabalho ao cinema brasileiro, após o tema ter sido escanteado na segunda metade 
dos anos 1980 e na década seguinte. Para os autores, esse recuo, no final do século 20 , tem a ver com o discurso neoliberal que desloca a centralidade social do trabalho, tornando-o disciplina individual. As políticas e governos neoliberais retiram direitos e minam vínculos coletivos e formas de solidariedade, antes narradas, por exemplo, no cinema de Leon Hirszman, tanto ficcional como documental5. O embate central de Indústria Americana (Estados Unidos, 2019), que ganhou em 2020 o Oscar de melhor documentário, é entre a empresa chinesa Fuyao, que produz vidros de carro e se instala na periferia de Ohio, e os trabalhadores que desejam se sindicalizar. Para o CEO da Fuyao, Cao Dewang, "Queremos evitar sindicatos. Se tivermos sindicato, nossa produtividade baixa [...]. Se um sindicato entrar, a fábrica fecha". ${ }^{6}$

Figueiredo, Siciliano e Miranda (2019) detêm-se sobre ficções como Arábia (Brasil, 2017), Corpo elétrico (Brasil, 2017) e Trabalhar cansa (Brasil, 2011) e concluem que, se a questão da opressão do trabalho é recuperada em nossa cinematografia, ela se dá por via menos coletiva que individual. Podemos estender essa percepção à ficção latino-americana, caso consideremos filmes como Roma (México, Estados Unidos, 2018) e A camareira (México, 2019), em que a crítica à exploração do trabalho é tecida no percurso das personagens. De todo modo, o fato de o trabalho tornar-se objeto da cinematografia contemporânea revela o aspecto de sua crise na sociedade. A condição de exploração, sofrimento e insegurança que a racionalidade neoliberal busca naturalizar, determinadas narrativas audiovisuais de ficção e documentais esforçam-se para desvelar. É significativo que o capítulo que abre a obra O privilégio da servidão, de Ricardo Antunes (2018, p.i.), "Fotografias do trabalho precário global", seja um conjunto de breves descrições de sete filmes, lançados entre 2015 e 2017, que "desmoronam os mitos da sociedade do tempo livre do capitalismo atual, ao mesmo tempo em que apresentam um mosaico do mundo do trabalho real que hoje se expande em 
escala planetária"7. Estou me guardando... deve ser apreendido nesse contexto cinematográfico como contribuição para o entendimento dessa razão global. O neoliberalismo, para Dardot e Laval (2017, p. 16), é uma razão global em dois sentidos: é mundial, isto é, vale para o planeta, e abarca "todas as dimensões da existência humana", não se limitando ao econômico. No entanto, ao mesmo tempo em que trata dessa questão global, o documentário de Marcelo Gomes é narrativa de singularidades, notadamente no tratamento audiovisual dado ao problema, como analisarei adiante.

Estudos críticos sobre o regime neoliberal (HAN, 2018; DARDOT; LAVAL, 2017) afirmam que essa racionalidade se utiliza de técnicas suaves de poder que não afrontam ou reprimem o indivíduo, mas gerem as vontades dele. As técnicas são motivadoras e afirmativas (prometem o desenvolvimento pessoal); não negadoras ou proibitivas. Essa é uma gestão sedutora das almas. "O management é um discurso ferrenho que usa palavras de veludo" (DARDOT; LAVAL, 2017, p. 345). Daí o caráter amigável e invisível desse poder, que conduz afavelmente os governados.

A hipótese já anunciada é a de que Estou me guardando... não apenas registra, em sua face observacional e por meio das entrevistas, a condição neoliberal e suas formas de exploração. Para além, torna visível as técnicas desse poder inteligente. Como na conhecida frase de Paul Klee sobre a função da arte, trata-se não exatamente de reproduzir o visível, mas de tornar visível o invisível. Nisso ele se difere de outros documentários como Gig, a uberização do trabalho (Brasil, 2018), que é tipicamente filme de entrevistas, com depoimentos de trabalhadores explorados e de especialistas. Em Estou me guardando..., esse desnudamento se dá pela voz do documentário, compreendida, a partir de Bill Nichols (2005, p. 50), como "aquilo que, no texto, nos transmite o ponto de vista social, a maneira como ele nos fala ou como organiza o material que nos apresenta".

Behemoth, de Zhao Liang (China/França, 2015); Machines, de Rahul Jain (Índia/Alemanha/Finlândia, 2016); Consumed, de Richard Seymour (Grã-Bretanha, 2016); Brumaire, de Joseph Gordillo (França, 2015); What We Have Made, de Fanny Tondre (França, 2016); Factory Complex, de Im Heung-soon (Coreia do Sul, 2015). 
Assim, a voz não se restringe ao comentário narrado - de fato, importante instância de Estou me guardando... -, mas o inclui. Para Nichols (2005, p. 50), "voz talvez seja algo semelhante àquele padrão intangível, formado pela interação de todos os códigos de um filme, e se aplica a todos os tipos de documentário". Aproxima-se do que a teoria literária denomina enunciação, refere-se ao modo como um texto constrói, pela linguagem, seus significados para além daquela voz que narra ou do discurso direto das personagens.

\section{Tempo expropriado}

A indústria da moda é continuamente denunciada pela exploração do trabalho. A razão óbvia disso é que parte dela de fato não possui escrúpulos e envolve trabalho infantil, escravo e/ou sub-remunerado terceiro-mundista. As denúncias são também forma de o consumidor bradar cidadania e se propor a exercê-la por meio do boicote a determinadas cadeias de loja. Uma blogueira de moda norueguesa chegou a chorar na série documental "Sweatshop - Dead Cheap Fashion" (Noruega, 2014), quando visitou uma fábrica de roupas no Camboja [sweatshop significa "fábrica de suor"] em que uma mulher ganha três dólares pela jornada de 12 horas de trabalho. Propõem-se o boicote, mas não se questiona verdadeiramente o consumo. Como critica a matriarca da família Lyons no episódio final da ótima série britânica Years and Years, não resistimos a uma camiseta que custa uma pechincha: "pois é boa para se usar por baixo, no inverno. O dono da loja ganha míseros cinco centavos de libra por ela. E um camponês, em algum lugar do mundo, 0,01 centavo. E achamos que está bom. Participamos desse sistema a vida toda"

Há também o capítulo "Angelina Jolie", de Gomorra, a reportagem de Roberto Saviano (2008) sobre a máfia na região da Campania, Itália. A passagem descreve a exploração da mão-de-obra em Arzano, sul do país, em que grandes grifes fazem leilões entre as fabriquetas para privilegiar aquelas que conseguem produzir mais 
barato e mais rápido as peças de roupa que circularão mundialmente, misturadas a artigos pirateados. Pasquale é o alfaiate que entra em choque após reconhecer, pela televisão, um terno de seda branca, feito por ele, no corpo da atriz Angelina Jolie, no tapete vermelho da cerimônia do Oscar. "O máximo e o mínimo. Milhões de dólares e 600 euros por mês" (SAVIANO, 2008, p. 49). A personagem para de costurar e torna-se caminhoneiro, transportando todo tipo de mercadoria para uma família de mafiosos. "O melhor costureiro do mundo dirigia um caminhão da Camorra entre Secondigliano e o Lago di Garda" (SAVIANO, 2008, p. 51).

A poesia parnasiana possui um mote que talvez nos ajude a compreender por que narrativas sobre a indústria da moda são eficazes para expor a miséria do trabalho. Trata-se da ideia de que a beleza é ainda mais ressaltada quando se apaga o suplício do labor. A forma deve disfarçar o emprego do esforço, como nos versos de Olavo Bilac. A narrativa sobre a indústria da moda é, ao contrário, a exposição das costuras e do avesso daquilo que serve a nossa otimização estética - como a cultura fitness e a cirurgia plástica (HAN, 2018). Ela denuncia o mundo real nas costas do desenho ideal, para usarmos metáfora de Ricardo Antunes (2018).

As belas imagens iniciais de Estou me guardando... remetem a essa otimização estética. Os travellings da abertura exibem totens gigantes de modelos à frente do agreste ao som do Largo do Concerto, de Bach. Há algo de defasado nessa publicidade cuja artificialidade é denunciada de imediato. Ela nos evoca, por exemplo, as colagens de Richard Hamilton no início da arte pop. Os totens são filmados depois por detrás, em sua armação e estruturação. Tem-se, assim, a publicidade e as costas dela, aquilo que, como estrutura, sustenta a beleza. No fim da sequência, o espectador é conduzido a Toritama por um motoqueiro que equilibra entre ele e o guidão grande quantidade de jeans - primeira imagem da precariedade. Essa abertura sintetiza e antecipa o dito e o contradito que perpassará a forma fílmica.

A exposição do maquinário nas facções nos fornece o quadro do fenômeno social. A cor predominante dos ambientes é azul, não somente pelo jeans, mas pelas 
pinturas quase sempre descascadas das paredes e as roupas dos trabalhadores, o que constitui uma paleta fílmica em certa medida homogeneizante de indivíduos e coisas. O modo como as máquinas, a fiação, os carretéis de linha, os fragmentos de tecido, entre outros elementos da produção do jeans, são enquadrados resulta em uma composição que, como escreve Janet Malcolm (2016) acerca da fotografia industrial de Thomas Struth, domestica uma multiplicidade de detalhes em uma imagem legível.

No entanto, a fotografia de Struth que registra exclusivamente máquinas pode ser mais bem evocada em imagens de Indústria americana e suas tomadas da fábrica da Fuyao. Não é o caso de Estou me guardando..., que, em sua legibilidade, compõe as cenas quase sempre com máquina e indivíduo. Este, nas facções, submetido àquela, uma vez que é extensão dos esforços repetitivos e maquinais intermináveis (corte, costura, raspagem etc.), que tanto angustiam o narrador-diretor.

Para György Lukács (2010), a descrição, técnica do romance realista, nivelava todas as coisas, tornando o humano par dos objetos inanimados. A composição em Estou me guardando... possui efeito semelhante, no que reside uma de suas técnicas de desnudamento do poder neoliberal. Lukács (2010, p. 175) valorizava a narração em detrimento da descrição, pois, segundo ele, o narrador hierarquiza e vincula as coisas à experiência humana, dando a elas "vida poética". A observação no documentário, contudo, não confina a representação, pois esta deve ser apreendida em uma estrutura narrativa maior, em que a todo tempo evoca-se o passado e também se aponta criticamente para a circularidade da comunidade presa ao trabalho, como o mito de Sísifo. A circularidade está na dimensão da passagem do dia: filmam-se os mesmos espaços de manhã e à noite, em trabalho contínuo. Na mesma órbita, a semana é sempre encerrada pela feira e, no prazo de um ano, o acontecimento festivo do Carnaval é interrupção para que tudo retorne como antes.

O espaço filmado do trabalho é, assim, indissociável do tempo. A luta histórica dos trabalhadores assalariados foi, segundo Renán Cantor (2019), pela 
separação entre o tempo do trabalho na fábrica e o tempo livre, o que resultou na conquista do turno de oito horas. Na cultura da classe trabalhadora, os indivíduos desfrutavam desse tempo livre de diversas formas: "jogando futebol, bebendo nos bares, criando bibliotecas populares, estimulando grupos contra o consumo de álcool, fomentando a publicação de livros, jornais e revistas de trabalhadores, organizando passeios [...]" (CANTOR, 2019, p. 46). O tempo livre foi, depois, tornado, pelo capitalismo, tempo de ócio, em que se estimula "o consumo individual e familiar" (CANTOR, 2019, p. 47), como na prática do turismo mercantil.

Estou me guardando... apresenta ao espectador o tempo expropriado, uma vez que o trabalho se estende sobre os outros âmbitos da vida, no caráter global da racionalidade neoliberal (DARDOT; LAVAL, 2017). O documentário narra essa expropriação do tempo por meio do espaço quando, por exemplo, mostra que, nas facções, o ambiente fabril constitui a própria casa, com pouca ou nenhuma distância entre a máquina de costura e a mesa posta em que se almoça ou janta, enquadradas num mesmo plano. O confisco do tempo é ainda reforçado pela já citada presença de crianças na cena, que brincam com o maquinário ou são constantemente advertidas pelos familiares de que estão em lugar impróprio e que devem sair dali. Em outras cenas, reflete-se sobre a mudança nas calçadas da cidade. Para o narrador-diretor, elas simbolizavam o tempo livre, "onde todos os dias se colocava a cadeira de balanço para esperar o tempo passar". Na cidade do jeans, a calçada é hoje ocupada por pessoas mais velhas que realizam a última etapa da produção, revisando e limpando as peças, ou seja, a calçada é, agora, "lugar onde se passa o tempo trabalhando".

Léo é uma personagem do documentário que provoca deslocamentos nessa racionalidade. Ele não está isolado nisso, pois é também possível identificar resistências em personagens como a senhora que afirma ser agricultora e parece desprezar a fabricação de jeans; o trabalhador mais experiente que, à diferença dos jovens, se mostra consciente de sua situação precária e planeja o futuro; ou o pastor de cabras que ainda toca o rebanho como nas memórias do narrador. No entanto, o modo como Léo atravessa o documentário, das primeiras cenas 
ao Carnaval na praia, atribui-Ihe significação. Uma das poucas personagens nomeadas, sua primeira aparição é dormindo, enquanto os outros trabalham. A personagem sente-se, então, flagrada e, na entrevista inicial, afirma sua condição de trabalhador e relata níveis de dificuldade de serviços braçais. O espectador assiste, de fato, em outras cenas, a Léo em constante atividade, não só com o jeans, mas também como pedreiro. Em determinado momento, fica-se sabendo que ele considera o capitalismo a raiz dos males ("dinheiro é a perdição deste mundo, fonte de todas as maldades") e que deseja integrar uma igreja, mas que, como gosta de tomar bebidas alcoólicas, não se adapta às regras da instituição. Uma de suas falas, que parece escapar, é desconcertante: "O meu problema não é a bebida, mas trabalhar". Nessa construção frasal, por um momento, invertemos a questão, abrindo a possibilidade de ver como problema não a bebida, mas a aberração naturalizada de que nesta sociedade "tudo na vida é trabalho".

\section{Autorreflexividade}

Estou me guardando... pertence a uma geração de documentários conscientes de seu gesto. Comecemos pela voz que narra, que não é evidentemente uma voz de deus. A voz de Marcelo Gomes é rouca, pequena e nostálgica. Como em outros documentários brasileiros recentes, conduzidos pela voz do/a diretor/a No intenso agora (Brasil, 2017) e Democracia em vertigem (Brasil, 2019) Estou me guardando... é uma narrativa com traços autobiográficos mas que não constitui propriamente uma autobiografia, uma vez que o narrador, ainda que implicado naquilo que narra, fala-nos também dos outros e de eventos socialmente compartilhados que ultrapassam sua vida. A autobiografia desliza para o outro. Essa é uma geração de documentaristas que sabe que a objetividade épica já teve seu efeito de verdade esvaziado e que, possivelmente, considera o filme de entrevistas (a enunciação direta das personagens) recurso fácil de tamponamento ideológico. Como critica Nichols (2005), muitas vezes o filme de entrevistas apenas esconde a voz do texto, mas continua, de forma autoritária, a hierarquizar e direcionar os testemunhos de modo pouco dialógico. 
A narrativa em primeira pessoa em Estou me guardando... se deve, contudo, menos à necessidade de afirmar um ponto de vista do que de manifestar o vínculo afetivo com aquilo que se narra. Esse vínculo diz respeito à motivação do documentarista e permite que o espectador compreenda - até onde é possível, dada a inconsciência do gesto - o impulso narrativo. De algum modo, esses documentários parcialmente autobiográficos são também sobre a formação de uma psicologia, sobre como ansiedades conduzem aos temas e como estes são elaborados a partir da vida dos diretores, muitas vezes com referência à infância e/ou aos pais dos realizadores.

Em Estou me guardando..., a voz do narrador-diretor coloca dois tempos em confronto. O espectador assiste somente às imagens da Toritama recente, mas recria, por meio da voz do diretor, o passado da cidade. Pela voz, sabemos, por exemplo, que, na infância de Gomes, o rápido pôr do sol encobria a cidade com melancolia, enquanto escutava-se a Ave Maria. Como contraponto, o presente fílmico exibe imagens de jovens em uma facção ouvindo e cantando Vida Loka, dos Racionais MC's: "Admiro os crentes, dá licença aqui/ mó função, mó tabela, pô, desculpa aí!".

Para além da oposição entre passado e presente, ativa-se, fundamentalmente, na narração, o contraponto entre memória e capitalismo. Cantor (2019, p. 61), ainda uma vez, ajuda-nos a compreender o que está em jogo aqui. Para o autor, no capitalismo, a memória perde a condição de "patrimônio crítico individual" e é instrumentalizada, como nos espaços para armazenamento do computador ou celular. Na lógica mecanicista, a memória tecnológica é o que se aciona para melhor desempenho. "Nessas condições, desaparece o ser humano como sujeito histórico, com vínculos profundos com seu passado pessoal e social, para reduzir-se a mero consumidor, que vive num presente eterno, sem antes nem depois" (CANTOR, 2019, p. 61). A narração de Gomes é uma forma de resistência ao presente capitalista e seu tempo comercial uma vez que recupera, ainda que por meio da linguagem, valores que Cantor, em diálogo com Pasolini, julga fundamental para os vínculos solidários: quietude, relações duradouras, possibilidade de contemplação, entre outros aspectos de um tempo lento. 
A voz do narrador-diretor aponta também para aspectos da mediação do documentário, dando-Ihe perspectiva autorreflexiva. É conhecida a declaração de Eduardo Coutinho em que o diretor afirmava não filmar os outros, mas sua relação com os outros (LINS, 2004). O registro da voz fora de campo de Marcelo Gomes entrevistando os trabalhadores indica a condição relacional do documentário. Os entrevistados, por vezes, manifestam eles mesmos a consciência da mediação e demonstram conhecer algumas das regras daquela interação: as falas devem ser objetivas e enfatizar o anedótico; é possível cortar e editar.

Em outra cena, a voz do narrador-diretor enuncia artifícios audiovisuais, concretizados na tela, para tentar mitigar o esforço repetitivo do trabalho:

Decido cortar o som. O barulho ensurdecedor das máquinas me angustia, me causa ansiedade. Agora [sem o som], é essa repetição desse movimento que me causa angústia. Coloco uma trilha sonora [retorna Largo do Concerto, de Bach, já usada na abertura]. O balé das mãos se move no compasso da música. Filmo de outro ângulo. A angústia da repetição permanece.

A cena rompe, mais uma vez, com a transparência do documentário, uma vez que explicita o manejo do criador. No entanto, o diretor pouco pode em face do gesto maquinal que irá angustiar também o espectador e apontar para a violência dessa relação de trabalho.

Por fim, convém descrever um último artifício explicitado ao espectador: a produção do documentário financia a família de Léo, que não havia conseguido dinheiro, para passar o Carnaval na praia. Em troca, o grupo filma o Carnaval - o tempo de lazer - enquanto a equipe permanece em Toritama e registra a cidade silenciosa como na memória de Gomes, há 40 anos. Na mudança de perspectiva, o grupo capta o tempo livre: a família e amigos tomam banho de mar e de mangueira, pescam, bebem, escutam música e brincam o Carnaval. Para Han (2018, p. 11), a palavra liberdade é relacional, pois "ser livre significa originalmente estar com amigos" (no alemão, freiheit - liberdade - e freund - amigos - possuem a mesma raiz). Mas como o próprio autor adverte sobre nosso momento histórico, "a liberdade terá sido episódica" (HAN, 2018, p. 9), um entreato entre coerções. 
Assim, as cenas finais do documentário retornam à condição submissa. Primeiramente, há um plano aberto da Toritama noturna, com a legenda: "Toritama, 365 dias para o próximo Carnaval". Seguem-se imagens de uma facção em trabalho durante noite chuvosa. Vê-se a mesma composição que marca o filme, em que máquinas e apetrechos, em grande quantidade de detalhes, estão em foco de forma precisa com o humano. Nas cenas finais, o rosto de Léo, com olhar triste e máscara de proteção de trabalho, funde-se às imagens de calças jeans que circulam em uma máquina sob trilha sonora fria.

\section{Algumas considerações finais}

O poder afável da racionalidade neoliberal atua, por meio da motivação, na formação e gestão da mente empreendedora, de lógica competitiva em que o sujeito se torna empresa de si mesmo. Esse é um poder invisível, uma vez que não é exercido de modo explicitamente opressor - mas no cultivo das vontades - e não identifica seu estrategista. Dissolve a noção de proletariado, vinculando o trabalhador, que se autoexplora, de forma mais direta ao capital. O modo como Estou me guardando... evidencia esse poder passa por sua voz tecida no conjunto dos artifícios audiovisuais. Considero que as entrevistas do documentário, a expressão direta dos trabalhadores submetidos ao neoliberalismo, registra essa racionalidade, no entanto, é a forma fílmica que a confronta.

Nestas considerações finais, gostaria de retomar alguns dos elementos do documentário que, no arranjo audiovisual, expõem aspectos do poder neoliberal. Primeiramente, destaco a composição fotográfica e como ela aponta para a expropriação do tempo. Ao enquadrar o humano na multiplicidade de máquinas e apetrechos do trabalho nas facções, descreve-se a equalização entre os sujeitos e as coisas e o consequente assujeitamento do indivíduo neoliberal, submetido a esforço repetitivo. Muitas cenas evidenciam os corpos suados na execução dos movimentos - a facção é uma sweatshop. Nesses espaços, percebe-se supressão do tempo livre seja por meio da contiguidade entre fábrica e lar, seja por meio da passagem do dia e da noite. A luta pelo tempo livre já não marca as relações 
de trabalho, uma vez que quanto mais o indivíduo explora a si mesmo, mais se vê como próspero.

A voz do narrador-diretor, de corte autobiográfico, não resulta em autobiografia, mas na exposição de vínculos afetivos com o mundo narrado. Ela abre possibilidades autorreflexivas, como na cena em que, ao comando do diretor, recursos audiovisuais são manejados para tentar, em vão, mitigar a angústia do maquinal. Ou, ainda, quando o dispositivo da filmagem é explicitado e as câmeras, durante o Carnaval, passam para as mãos da família de Toritama que viaja ao litoral. Como vimos, a voz do narrador-diretor é também expressão memorialística. Como manifestação de um passado pessoal e afirmação de um sujeito histórico, ela interroga o presente contínuo do neoliberalismo.

Assim, nesse documentário, passa-se de uma reflexividade a outra. Isto é, parte-se de uma consciência audiovisual para romper a transparência de coerções que não se revelam de imediato. A opacidade fílmica torna-se método de investigação social.

\section{Referências}

ANTUNES, R. O privilégio da servidão. São Paulo: Boitempo, 2018 (formato epub).

CANTOR, R. V. A expropriação do tempo no capitalismo atual. In: ANTUNES, R. (org.). Riqueza e miséria do trabalho no Brasil IV. São Paulo: Boitempo, 2019.

DARDOT, P. LAVAL, C. A nova razão do mundo. São Paulo: Boitempo, 2017.

FIGUEIREDO, V. SICILIANO, T. MIRANDA, E. O tempo subtraído: cotidiano e trabalho no cinema brasileiro do século XXI. In: Anais. XXVIII Encontro Anual da Compós, Porto Alegre, 2019. 
FONTES, V. Capitalismo em tempos de uberização. Marx e o marxismo, v. 5, n. 8, jan.-jun., 2017.

HAN, B.C. Psicopolítica. Belo Horizonte; Veneza: Âyiné, 2018.

LINS, C. O documentário de Eduardo Coutinho. Rio de Janeiro: Jorge Zahar, 2004.

LUKÁCS, G. Narrar ou descrever? In: LUKÁCS, G. Marxismo e teoria da literatura. 2a. ed. São Paulo: Expressão Popular, 2010.

MALCOLM, J. Profundidade de campo. In: MALCOLM, J. 41 inícios falsos. São Paulo: Companhia das Letras, 2016.

NICHOLS, B. A voz do documentário. In: RAMOS, F. (org.). Teoria contemporânea do cinema: documentário e narratividade ficcional. v. 2. São Paulo: Editora Senac, 2005.

SAVIANO, R. Gomorra. Rio de Janeiro: Bertrand, 2008.

Submetido em: 23 out. 20 | aprovado em: 22 nov. 20 